\title{
Are Humans Prepared to Detect, Fear, and Avoid Snakes? The Mismatch Between Laboratory and Ecological Evidence
}

\author{
Carlos M. Coelho', Panrapee Suttiwan ${ }^{1}$, Abul M. Faiz ${ }^{2}$, Fernando Ferreira-Santos ${ }^{3}$ and \\ Andras N. Zsido ${ }^{4 *}$ \\ 'Department of Psychology, Faculty of Psychology, Chulalongkorn University, Bangkok, Thailand, ${ }^{2}$ Department of Psychology, \\ Dev Care Foundation, Dhaka, Bangladesh, ${ }^{3}$ Department of Psychology, Laboratory of Neuropsychophysiology, Faculty of \\ Psychology and Education Sciences, University of Porto, Porto, Portugal, ${ }^{4}$ Department of General and Evolutionary \\ Psychology, Institute of Psychology, University of Pécs, Pécs, Hungary
}

\section{OPEN ACCESS}

Edited by:

C. David Navarrete,

Michigan State University,

United States

Reviewed by: Hisao Nishijo,

University of Toyama, Japan

Thomas John Hossie,

Trent University, Canada

*Correspondence:

Andras N. Zsido

zsido.andras@pte.hu

Specialty section:

This article was submitted to Evolutionary Psychology,

a section of the journal

Frontiers in Psychology

Received: 10 April 2019

Accepted: 28 August 2019 Published: 11 September 2019

Citation:

Coelho CM, Suttiwan P, Faiz AM,

Ferreira-Santos F and Zsido AN

(2019) Are Humans Prepared to

Detect, Fear, and Avoid Snakes? The

Mismatch Between Laboratory and Ecological Evidence.

Front. Psychol. 10:2094.

doi: 10.3389/fpsyg.2019.02094
Since Seligman (1971) statement that the vast majority of phobias are about objects essential to the survival of a species, a multitude of laboratory studies followed, supporting the finding that humans learn to fear and detect snakes (and other animals) faster than other stimuli. Most of these studies used schematic drawings, images, or pictures of snakes, and only a small amount of fieldwork in naturalistic environments was done. We address fear preparedness theories and automatic fast detection data from mainstream laboratory data and compare it with ethobehavioral information relative to snakes, predatorprey interaction, and snakes' defensive kinematics strikes in order to analyze their potential matching. From this analysis, four main findings arose, namely that (1) snakebites occur when people are very close to the snake and are unaware or unable to escape the bite; (2) human visual detection and escape response is slow compared to the speed of snake strikes; (3) in natural environments, snake experts are often unable to see snakes existing nearby; (4) animate objects in general capture more attention over other stimuli and dangerous, but recent objects in evolutionary terms are also able to be detected fast. The issues mentioned above pose several challenges to evolutionary psychology-based theories expecting to find special-purpose neural modules. The older selective habituation hypothesis (Schleidt, 1961) that prey animals start with a rather general predator image from which specific harmless cues are removed by habituation might deserve reconsideration.

Keywords: general feature detection, modular theories, snake bite kinematics, selective habituation hypothesis, evolutionary psychology

\section{INTRODUCTION}

Worldwide, yearly snakebites leading to death could be as high as 94,000 (Kasturiratne et al., 2008) or even more according to the World Health Organization. The annual number of fatalities can be as high as 125,000, with an additional 400,000 amputations and other severe health consequences (World Health Organization, 2013). Considering these numbers, one may argue that snakes to date pose a real threat to human survival, and thus, a specific defense system 
might have been adaptive throughout the course of primate evolution. Indeed, many studies have shown that humans and other primates might have an attention bias toward evolutionary threats such as snakes. Some researchers (Öhman and Mineka, 2003; Isbell, 2006) consider that humans might have a dedicated "threat-detection" or "snake detection" module that favors both faster detection and fear learning of material related to snakes.

The present manuscript collects information about snake behavior and kinematics as well as epidemiological information from countries where snakebites are more frequent or better described. Our aim is twofold: (1) describe the circumstances snakebites usually take place and (2) find out whether this information can help us support or refute the general assumption that humans have a unique ability to detect snakes, even under camouflage conditions, due to a specific snake defensive mechanism.

\section{MODULAR THEORIES RELATIVE TO SNAKES}

What are the salient features of dangerous objects that are missing in similar, but harmless ones? Since 1937 experiments are done, intending to know how we are able to discern what a life-threatening animal looks like (see Schleidt et al., 2011). Seligman (1971) proposed that a vast majority of phobias would relate to particular objects and events essential to the survival of the human species. Seligman's paper prompted scientists to test his theory, using pictures of snakes and other potentially harmful animals (Öhman et al., 1974). This line of research later culminated in a theory that humans have a perceptual apparatus to efficiently detect snakes and other threats (Öhman and Mineka, 2003), even under challenging visual conditions (Soares et al., 2014; Kawai and He, 2016) due to the evolutionary value of this ability (see Soares et al., 2017 for a review).

LeDoux suggested the possibility of a "visual bypass" (LeDoux, 1998) to convey rapid visual information to the amygdala and protect humans from, for instance, snakes. This was based on an earlier finding (LeDoux et al., 1990) that the auditory cortex is not required for a sound to be paired with a shock during fear conditioning, as projections from the acoustic thalamus are sent directly to the amygdala. However, the visual bypass is less sharp as it does not benefit from cortical processing. As such it is a crude representation of the stimulus, LeDoux calls it a "quick and dirty processing pathway" (LeDoux, 1998, p. 164) that could lead to a number of false positives discoveries. LeDoux (1998) and others (see e.g., Flykt, 2006; LoBue, 2014) argued that it is nonetheless better to err on the side of caution than to wait until the cortex figures out whether the object is a snake or a curved stick.

Not much later, it was further shown that humans could discriminate visual stimuli that are not consciously perceived, due to connectivity between the right amygdala and the superior colliculus and the pulvinar nucleus of the thalamus (Morris et al., 1999). This circuit became known as the low road, a route able to "avoid" a longer cortical route since it goes directly to the amygdala from the superior colliculus and the pulvinar nucleus of the thalamus. The combined findings gave additional vivacity to a theory of fear, based on a low road, and many researchers use this idea to explain their results. Moreoverd, additional research supported that humans could respond to masked stimuli of snakes (Öhman and Soares, 1994) with an enhanced physiological fear response. The recognition of the snake stimulus (presented for $30 \mathrm{~ms}$ ) had been prevented by an immediately following masking stimulus, presented for $100 \mathrm{~ms}$. Still, participants with a fear of snakes showed enhanced skin conductance to both the masked and the unmasked pictures of snakes (presented for $130 \mathrm{~ms}$ ), although they were not able to consciously identify the masked ones.

The low road gave additional vivacity to theories of fear (but cf., Pessoa and Adolphs, 2010) suggesting the existence of a quick visual pathway designed to facilitate detection of a threat as a first signal that something dangerous might be present. Thus, preparing the person to deal with a potential hazard even before it reaches awareness. In support of this view, Van Le et al. (2013) showed that the pulvinar response latency to snake pictures was shorter (within $50 \mathrm{~ms}$ post-stimulus onset) and faster than response latencies to other visual stimuli, such as faces and geometrical shapes, and was associated with a significant increase in gamma band oscillations in pulvinar neurons (Van Le et al., 2016).

This previous body of work specifies that a subcortical visual route operates independently of the cortex, having a role in pre-attentive affective processing, by providing a rapid direct pathway to the amygdala for snake-detection. Indeed, it has been argued that snakes seem to elicit fast behavioral responses, facilitating rapid detection, focused attention, and avoidance in humans and other primates (Maior et al., 2011; Soares, 2012; Van Le et al., 2016). Overall, several theories favor that humans have a set of prewired responses embedded in an evolved brain circuit or dedicated modular system built up over phylogeny which allows for faster detection of snakes, comparatively to most other stimuli. This idea feeds from a more general impression that the brain is composed of highly selective and functionally specialized areas connected along developmentally and evolutionarily dedicated pathways (see Anderson, 2016; Badcock et al., 2016). But some data are inconsistent with the modular theories, as we will address next.

\section{DATA INCOMPATIBLE WITH MODULAR THEORIES}

1. Considering that it is better to err on the side of caution than to wait until the cortex figures out whether the seen object is a snake or a curved stick, people should be afraid of all kinds of snakes or snake-like animals and objects. Indeed, it has been suggested (Larson et al., 2007, 2009, 2012; Van Strien et al., 2016) that curved lines and curvilinear shapes have an advantage in visual processing. Respondents seem faster to find a curved line as targets among straight lines compared to when they had to find a straight line among curved ones. Furthermore, curvilinear shapes are also detected faster than rectilinear (V-shaped) shapes when they had to be found among the same set of distractors, i.e., straight lines or circles. 
False alarms (e.g., looks like a snake but after all it is a $\log$ ) are less costly than false negatives (e.g., looks like a $\log$ but it is a snake); thus, it is safer to err on the side of excessive defensive expression (see e.g., LeDoux, 1998; Nesse, 2001). However, if the system is built to be overdefensive and err to the side of false positives, it should respond not only to snake-specific cues but also to other similar threat-related stimuli because many non-venomous snakes mimic venomous snakes, and venomous snakes exhibit extreme pattern variability and different characteristics (e.g., Wüster, 1998). For example, young white-faced capuchin monkeys (Cebus capucinus) are known to utter false alarm calls at a wide range of harmless non-predator animals (e.g., indigo snakes) compared to adults, and snake-species discrimination does not become apparent until the juvenile stage (Meno et al., 2013). Similarly studies with vervet monkeys (Chlorocebus pygerythrus) (Seyfarth and Cheney, 1980) and with spectral tarsiers (Tarsius spectrum) (Gursky, 2003) found youngsters to provide false alarm calls triggered by a wide range of harmless animals or objects, suggesting that this predator-recognition process likely involves experiential and vicariant learning refinements (Meno et al., 2013). Another example is given by the forest-living Campbell's monkeys (Cercopithecus C. campbelli) that vocalized to the presence of familiar Gaboon vipers but not to unfamiliar black mambas (Dendroaspis polylepis), unreported in the Tai forest where the study was performed (Ouattara et al., 2009).

2. Previous research has shown (see e.g. Subra et al., 2018; Zsido et al., 2018a) using various paradigms that a modern threatening stimulus could lead to similar behavior as an evolutionary relevant one. For instance, when modern (e.g., gun) and evolutionary (e.g., snake) targets are compared directly in the classical visual search task proposed by Öhman and colleagues (see e.g., Öhman et al., 2001), the modern threatening target caught participants attention faster than evolutionary ones (Zsido et al., 2018b).

3. Low-level features of the visual stimulus could have affected many of the previous findings, as contrast/luminance and spatial frequency affect visual detection speed and processing of emotional content during early visual stages (Vlamings et al., 2009; Quinlan, 2013). Most studies did not control for low-level features of the visual stimulus (including contrast) of snakes, which can be significantly different from those of other categories and can affect the findings. These effects of contrast equalization on spatial frequency processing are particularly crucial during early (i.e., < $100 \mathrm{~ms}$ ) visual processing (McFadyen et al., 2017).

4. In tropical and subtropical countries, envenoming affects mainly people involved in occupations and lifestyles requiring movements in a dense land, such as farmers, herders, labourers, hunters, shepherds, and workers (Meenatchisundaram and Michael, 2009). However, most of the previous work relied on controlled laboratory paradigms without support from studies in naturalistic conditions, which may be the cause of many sorts of potential bias (Quinlan, 2013; Paré and Quirk, 2017).

5. Many snakes pigmentation pattern appears to be strongly influenced by selection to avoid visually oriented predators
(Jackson et al., 1976). Snakes rely on crypsis - (i.e., background matching) to become indistinguishable from the surrounding background (Isaac and Gregory, 2013) as one of many strategies to avoid detection (see Allen et al., 2013).

So even highly experienced observers with over 20 years' experience miss seeing most snakes (more than 75\%) aboveground around them in a flat and lightly vegetated area (Whitaker and Shine, 1999a,b). However, this could also suggest that snakes developed crypsis since the primate visual system was so effective to detect snakes.

6. Most snakebites follow at very close vicinity (Whitaker et al., 2000; Clark et al., 2012) and are extremely fast (Cundall, 2002; LaDuc, 2002; Clark et al., 2012; Penning et al., 2016), outside the capability for humans to escape.

7. There is evidence supporting that the human right amygdala is a specialized neural adaptation dedicated to processing visual information about animals in general (Mormann et al., 2011), which could represent either predators or prey, such as snakes. Indeed, humans do kill and eat snakes in several cultures (Headland and Greene, 2011). It seems likely that human's enhanced detection of snakes is not so much contributing toward a significant escape advantage, but it might instead favor attention and further evaluation (Purkis and Lipp, 2007). When a stimulus needs to be approached in one situation may be avoided in another (Mesulam, 1998), the brain is more adapted to behavioral flexibility than to automatic, modular responses. In the case of snakes, the evidence seems to point to a similar conclusion.

8. Various laboratory studies comparing snakes and spiders (animate objects) as prepared stimuli with flowers and mushrooms might have been flawed by animacy as a confound. Flowers and mushrooms "behave" similarly to inanimate objects (e.g., coffee mugs and telephones). Change-detection, for instance, is slower and less precise for inanimate targets, even when the inanimate targets can potentially move (e.g., tools or cars) or have evolutionary relevance such as plants or fruits (New et al., 2010; Jackson and Calvillo, 2013). This evidence does not necessarily deny the snake detection theory, but previous papers using flowers and mushrooms are often used and cited to support the snake detection theory (e.g., Soares et al., 2017).

9. Some of the characteristics of human-snake interaction do not appear to be the ones commonly seen between preypredator interactions that lead to specific evolved automated traits. Ultra-specializations make sense for ultra-dependent predator-prey interactions, such as the kangaroo rat-rattlesnake interaction. These rodents escape speed may have evolved in response to snake predators (Higham et al., 2017), as Mohave rattlesnakes (Crotalus scutulatus) show very fast accelerations (up to $362 \mathrm{~ms}^{-2}$ ) requiring from the kangaroo rats a response around $61.5 \mathrm{~ms}$ in order to escape. Although humans evolved the large cortex that could modify instinct behaviors, these take time and reduce the automaticity and response speed.

10. Finally, Grassini et al. (2016) found that snakes need to be consciously perceived to elicit emotion. Furthermore, it was also shown that affective processing requires awareness (Lähteenmäki et al., 2015). 
The abovementioned discussion points raise the question of why and how humans would develop an ultra-fast detection mechanism specific to snakes. In the next part of the paper, we present some information about snakes that hopefully can assist in disentangling this problem.

\section{SNAKES AND SNAKEBITES}

A few species of snakes are responsible for most fatal snakebites. The most reported are the (1) Krait (Bungarus caeruleus); (2) Saw-scaled viper (Echis carinatus); (3) Russell's viper (Daboia russelii); (4) Cobra-Spectacled Cobra (Naja naja), and Monocled Cobra (Naja kaouthia) (e.g., Punde, 2005; Bawaskar et al., 2008) which will be next briefly described as examples. Some information from Rattlesnakes (Crotalus) kinematics, Eastern Brownsnake (Pseudonaja textilis), and Cottonmouths (Agkistrodon piscivorous) crypsis are also addressed. Other particular species are punctually mentioned when relevant.

\section{Common Krait (Bungarus caeruleus)}

The krait is a nocturnally active snake that lives close to human dwellings (Deshwal and Gupta, 2015). Although usually not aggressive, it often creeps into farmer's habitations to feed on rodents (Bawaskar et al., 2004). This leads bites during involuntary sleep movement (Ariaratnam et al., 2008) while snakes benefit from people's body heat (Bawaskar and Bawaskar, 2015). This particular interaction suggests that this snake is likely unrelated to any selective pressure to primates' evolution of some form of visual detection bias.

\section{Russell's Viper (Daboia russelii)}

Russell's viper is distributed throughout Southeast Asia (Pathan et al., 2015). This snake is usually about $120 \mathrm{~cm}$ and typically does not strike unless provoked, before which it hisses a loud warning (Odedara, 2007). However, its bite presents high morbidity and mortality rates (Alirol et al., 2010; Sharma et al., 2014). Russell's viper is nocturnal, and bites occur during the early day and at dusk, affecting farmers in agricultural lands usually when in paddy fields, clearing bushes, cutting grass in home gardens, walking unprotected on narrow footpaths, growing grass or jungle tracks (Kularatne, 2003; Kularatne et al., 2011, 2014). The bite mostly happens when the snake is stepped on (Ariaratnam et al., 2009). Interestingly, when people intentionally search for snakes, such as field herpetologists and collectors, they need to look under rocks, logs, boards, sheet metal, and debris, as well as collapsed buildings, where refuge places abound to be able to find these reptiles (Fitzgerald, 2012) as snakes are not easy to spot.

The Russell's viper snakebite characteristics might make it a candidate to have been an evolutionary selective pressure. It appears to be a snake challenging to discover and additionally it emits a warning sound before striking. It would be important to know if people that are bitten were previously "warned" by the snake and if they are able to detect them in the abovementioned terrains.

\section{The Indian Cobras, Spectacled Cobra (Naja naja), and Monocled Cobra (Naja kaouthia)}

The cobras of the genus Naja are distributed throughout most Asian countries and usually range from 100 to $150 \mathrm{~cm}$. Cobras usually feed on rodents, frogs, toads, birds, lizards, other snakes, and eggs (Wüster, 1998). They can be found in termite nests, holes in dams of rice fields, stonework constructions, and tree base roots. The monocled cobra is also a significant life-threatening source but not aggressive, always attempting to escape and offering plenty of warning before biting even when cornered (Wüster, 1998). The fact that bites occur during daytime and dusk hours and include areas of human development (toilets, houses, etc.) and natural areas (bushes, trenches, water reservoirs, etc) (Rahman et al., 2010; Bawaskar and Bawaskar, 2015) suggests that these are being defensive bites that occur when both the human and the snake were not "expecting" each other.

\section{Saw-Scaled Viper (Echis carinatus)}

The Saw-scaled Viper size is responsible for the most significant number of snakebite cases (Warrell, 1995): usually, less than $45 \mathrm{~cm}$ long, very cryptic, bites under small provocation (Odedara, 2007) very quickly, averaging 69 ms (20-108 ms) (Cundall, 2017, personal communication). This snake often bites farmers, hunters, labourers, and persons walking barefoot in the jungle and rocky areas. Often the victim interprets the injury as being caused by a thorn, failing to notice the bite (Bawaskar and Bawaskar, 2015).

The saw-scaled viper snakebite characteristics make it a strong candidate to have been a potential selective pressure responsible for the development of a particular detection module in the primate visual system. Many people do not see the snake in time to avoid being bitten but one can argue: "imagine how many venomous snakes would bite even more if we did not have this ability?" To better understand this problem, it would be essential to collect information about how many strikes were avoided and in what conditions. How many snakes people are able to see and avoid comparatively to other potentially dangerous animals?

\section{Crypsis}

Snakes are cryptic animals usually immobile if buried and fleeing if at the surface (Maritz, 2012). Whitaker and Shine (1999a) recorded the responses of free-ranging Brown snakes to 455 close encounters with humans. They implanted miniature radio transmitters in 40 snakes in agricultural landscapes area and found that in about half of the encounters the snake retreated or relied on crypsis. Moreover, snakes advanced offensively toward the observer on only three occasions. Similarly, in a study (Gibbons and Dorcas, 2002) with Cottonmouths, most snakes tried to escape when confronted.

We next address some relevant information about snakebites concerning their strike kinematics and later compare it to the human response reaction times.

\section{Snake Strike}

Functional morphology studies on snake strike kinematics often divide the strike into four phases namely: (1) preparation, 
(2) extension, (3) contact, and (4) release (Kardong and Bels, 1998). Strike kinematics divided into different stages (Kardong and Smith, 2002), but here we collected information considering the method of division in four phases.

The viperid strike is probably the best studied, usually starting from a coiled position and rapidly straightening the forefront of the body to carry the head toward the prey (Kardong and Bels, 1998). Laboratory data on strikes reveal a typically predatory strike range of 3-20 cm and extension phases between 20 and $50 \mathrm{~ms}$ (Clark et al., 2012). A recent study (Penning et al., 2016) revealed strike extension phase durations between 48 and $84 \mathrm{~ms}$ in distances between 8.6 and $27.0 \mathrm{~cm}$ in several snake species, and western diamond-backed rattlesnakes (Crotalus atrox) accelerations could reach $279 \mathrm{~ms}^{-2}$. Another in situ studies (Clark et al., 2012) observed 37 predatory extension recordings, which revealed extension phase durations between 20 and $100 \mathrm{~ms}$ in distances between 5 and $50 \mathrm{~cm}$, in several snake species of Crotalus (rattlesnakes). Successful strikes typically started from a distance less than $15 \mathrm{~cm}$ of the prey. A study from Whitaker et al. (2000) with the Brown snake shows an overall mean strike duration of $0.28 \mathrm{~s}(\mathrm{SD}=0.12)$ and a strike mean distance of $34 \mathrm{~cm}$, between 12 and $64 \mathrm{~cm}$ in defensive strikes toward approaching humans. A study from Araújo and Martins (2007) regarding defensive strikes in five species of lanceheads of the genus Bothrops (Viperidae) revealed average strike distances of about $10 \mathrm{~cm}$ and a strike duration of about $100 \mathrm{~ms}$, with $B$. alternatus being the fastest, $80.6 \mathrm{~ms}$ (66.7-110.0).

In sum, most snake bites occur in very close proximity to the prey, typically from 3 to $20 \mathrm{~cm}$, and defensive strikes up to $50 \mathrm{~cm}$ (Clark et al., 2012) or $60 \mathrm{~cm}$ (Whitaker et al., 2000). Furthermore, they are extremely quick, usually below $100 \mathrm{~ms}$, both in predatory (Cundall, 2002; Clark et al., 2012) and defensive modes (LaDuc, 2002; Penning et al., 2016). Overall, the data show very variable values, but still very fast compared to human reaction times, as we will see next. These velocity values also suggest that the detection advantage needs to happen when the human is still far enough from the snake to have time to avoid it, and this distance should be more than $60 \mathrm{~cm}$, or about "one step" away from the snake.

\section{HUMAN RESPONSE SPEED TO DETECT AND AVOID SNAKES}

Amygdala modulation of responses by the affective content of stimuli was observed to start at around 200 ms (KrolakSalmon et al., 2004), although quick amygdala responses can begin as early as $74 \mathrm{~ms}$ post-stimulus onset (Méndez-Bértolo et al., 2016). Humans could show autonomic responses in response to unconscious fearful objects through a subcortical fear module that could respond in very short latencies (Silverstein and Ingvar, 2015). Although strong enough evidence is lacking, some previous studies showed prefrontal response to emotional stimuli in less than $100 \mathrm{~ms}$ post-stimulus onset (see e.g., Carretié et al., 2004; Rehbein et al., 2014). The actual duration of visual processing itself is likely to be around 100-150 ms post-stimulus (Thorpe et al., 1996; VanRullen and Thorpe, 2001; Liu et al., 2009). However, the response time to a snake (e.g., pressing a key) image takes about $400 \mathrm{~ms}$ (Haberkamp et al., 2013), a result similar to the one reported by Thorpe et al. (1996) for general image categorization. Search times to find a snake among other distractor stimuli take nearly 1,000 ms (Öhman et al., 2001). Note that, for example, the findings of Flykt and colleagues (e.g., Flykt and Caldara, 2006; Flykt et al., 2012, 2017) do not support an involvement of early information processing in the detection of the feared animal in fearful participants, they favor that short response time to biological threats are mostly due, not to fast detection, but to motor preparations to threats. In sum, they find that a more elaborate analysis of these complex stimuli is required to achieve the detection of the feared animal in fearful participants (Flykt and Caldara, 2006); that focused attention can lead to increases in manual force (Flykt et al., 2012); and that they provide no support for the notion that fear responses can be triggered by stimuli presented outside awareness (Flykt et al., 2017).

More recently, Van Strien et al. (2016) followed similar standard procedures for visual search tasks but comparing simple curvilinear with rectilinear shapes (among straight line distractors). Search times were now reduced compared to the previous more complex figures (Öhman et al., 2001) and further reduced after fear induction, but still around $600 \mathrm{~ms}$. The results can be interpreted in terms of response to threatening stimuli. However, the search times do not seem to translate in a quick-enough response to bring any significant advantage when dealing at close proximity with snakes. As we have seen, the entire snake strike sequence often occurs in less than $100 \mathrm{~ms}$. Moreover, the abovementioned laboratory studies were mainly conducted using hand reaction times, which travel a shorter route compared to lower extremity limbs which exhibit delayed reaction times (Pfister et al., 2014) and is where snakes most often bite (e.g., Reid, 1975; Currie et al., 1991; Hansdak et al., 1998).

A recent work showing monkeys are responsive to visual cues of snake scales (Isbell and Etting, 2017) is one of the few ecologically valid studies so far. These results support the claim that vervet monkeys skillfully detect and remember snakes in the wild. This experiment was partially replicated with humans (Van Strien and Isbell, 2017) but again only in laboratory conditions.

\section{NON-MODULAR THEORIES}

The possible existence of a fear module (Öhman and Mineka, 2003) for snake detection ought to be validated (or refuted) in an ecologically valid context. In a natural environment, detecting the shared characteristic of many potential predators and natural dangers such as a looming motion, scales, curves or sharpness, makes perfect sense. Many other animals with scales and fangs that slither or crawl can cause damage and infections, such as some lizards, spiders, scorpions, centipedes, 
lepidopteran larvae, and gastropods. Consequently, a wide range of innovative structures has evolved to facilitate the delivery of venoms, such as "barbs, beaks, fangs modified teeth, harpoons, nematocysts, pincers, proboscises, spines, sprays, spurs, and stingers" (Casewell et al., 2013, p. 219). Considering the multitude of threat sources, it seems to be more useful to have a general preparedness (see e.g., Davey, 1995; Coelho and Purkis, 2009; Zsido et al., 2018a,b,c) to detect and respond to animate or sharp objects in general. Evolving a module for each of these animals or features would be impractical. Furthermore, it would also risk that the evolutionary time to build up a particular brain module could very well take longer than the existence of this potential predator, due to other selective pressures.

The animate monitoring hypothesis suggests that animate objects in general capture more attention-for their significance ever since human ancestral environments-over other stimuli (New et al., 2007; Nairne et al., 2013; Altman et al., 2016; Calvillo and Hawkins, 2016). Thus, providing another explanation to why humans might detect snakes quickly in laboratory tasks. However, this theory is not able to explain why, for example, people can detect guns faster (e.g., Zsido et al., 2018b) or why snakes are detected faster than birds (e.g., Van Strien and Isbell, 2017).

The selective habituation hypothesis (Schleidt, 1961) predicts that prey animals start with a rather general predator image from which specific harmless cues are removed by habituation. Form an evolutionary point of view, a neural mechanism for fast detection of threats would capture only general potential harms (e.g., simple curvilinear shapes) that could signal the presence or a threat, instead of particular and unique snake-like features, and then become specialized with experience. This model predicts that initially animals will be pre-programmed to be alert and scared of many stimuli. Then, this preparedness will generate costs from false alarms but not from missed detections. It does not require experience with the predator since any unusual cue that falls within a certain predator class elicits a response. But by selective habituation-learning what not to fear-potential preys pursue a more advantageous strategy (Deecke et al., 2002). Similarly, for example, the innate avoidance of coral snakes by birds extends to other toxic or harmless snakes and caterpillars (Janzen et al., 2010). Although it has only been shown with domestic chicks, there is evidence that innate fear responses might reset if enough time elapses between encounters with snakes or snake-like animals (Skelhorn et al., 2015).

The data and results collected in the present review favor the selective habituation hypothesis (Schleidt, 1961), i.e., prey animals start out with a rather general predator image from which specific harmless cues are removed by habituation. These models also match with Rachman (2002) suggestion that people gradually obtain the required abilities to deal with their current predisposed fears through habituation and experience. The environment can work, therefore, toward eliminating biologically relevant fears, which are likely not specific (e.g., snake), but more general (e.g., looming, scales, or sharpness) and according to context.

\section{CONCLUSION}

The present study gathered information from (1) snake behavior and strike acceleration, (2) bite circumstances, (3) crypsis; (4) human visual speed processing for detection of complex figures, (5) human reaction time when responding to images of snakes, as well as the fact that (6) snakes are common prey to humans. These are still challenges to the fear module theory or any theory that favors snakes detection advantage, resulting in an expressive way, in successful avoiding venomous snakebites or contributing with a significant escape advantage.

It seems likely that an innate ability exists to respond to simpler features, such as relative speed, size, and contrast of moving objects, before discrimination between different kinds of snakes or snakelike objects. If so, infants might have a predisposition to pay attention to everything sharp and become more specialized over time and experience. Animals and humans may become frightened by many stimuli with different physical, yet similar other characteristics that are not species-specific but rather associated with the context of predation, e.g., movement, intensity, duration, suddenness, or proximity (Boissy, 1995; Davey, 1995; Coelho and Purkis, 2009). Predation in primate populations includes 176 species of confirmed or potential predators of primates, from birds to mammals, reptiles, and sharks (Hart and Sussman, 2005). As such, it seems unlikely that humans have a special brain module for detection of a particular species. Moreover, many non-venomous snakes look like noxious ones, and many venomous snakes exhibit extreme pattern variability and different characteristics (e.g., Wüster, 1998). This led us to doubt the hypothesis that there is a proneness to detect venomous snakes over other snakes or snake-like animals like worms. In fact, several previous studies (Cave and Batty, 2006; LoBue et al., 2010; LoBue and Rakison, 2013; LoBue, 2014) claimed that low-level perceptual features commonly found in threatening stimuli might be detected very quickly by the human visual system. Nonetheless, we should also note that a long history of primate-snake competition could create a particular evolutionary environment unlike the ones existing with other animals (see Isbell, 2006, 2009). In this case, it is also possible that the aposematic coloration (Poulton, 1890) found in some snakes might have had a role inducing avoidance from humans as snakes predators, signaling their noxiousness, particularly in large size snakes (Niskanen and Mappes, 2005) more unable to be cryptic. Albeit fear of snakes does not seem to be influenced by aposematic coloration (Prokop et al., 2018), it does increase human attention, although experimental work by Niskanen and Mappes (2005) has shown that at least some snake color patterns may be aposematic without strongly reducing crypsis.

This review also noticed that snake bites are mainly due to the lack of early visual contact with the snake, and only some bites occur during clear visual contact, when the victim is aware of the snake and deliberately handling the animal (e.g., Minton, 1996; Chippaux, 1998; Hossain et al., 2010). It seems that a fast detection mechanism is only useful at a certain distance, and it would be important to know that distance. Predators can attack rapidly leading the potential prey to evolve anti-predator behavior that allows avoiding them (Clark et al., 2012). 
Nonetheless, the fact that parasympathetic activation-freezingcould also be an automatic and adaptive response (Campbell et al., 1997) to evolutionary threatening stimuli should be noted. Fear bradycardia-slow heart rate-is considered an adaptive response to predators when they are about to attack because the lack of movement may prevent the animal to carry out the intended action.

Some characteristics of human-snake interaction presented here could be argued as favoring the snake detection theory. As snakes are more likely to bite when people are sleeping, or when they are moving about in obscuring vegetation, or when light conditions are low can be seen as evidence that people are bitten because they had no chance to detect the snake. Thus, a modular theory would claim that a non-conscious, fast visual detection, involving the superior colliculus and pulvinar, should allow us to suddenly stop in our tracks before we take a fatal last step. It is not a conscious action, but one that keeps us safe until the slower conscious visual system will enable to actually become aware of the snake. Considering the lack of "sharpness" relative to the first fast visual detection could make us too prone to false positive alarms, and anything similar to a snake would trigger a false alarm. Nonetheless, most situations in which snakes bite people suggest either a total impossibility of escape from the bite-e.g., while sleeping, poor visibility at night, or accidentally stepping a snake while working-or lack of care. If the person is too close when detects the snake, and it is already initiating a strike, there is no likelihood of escape. In contrast, if the snake is detected before one reaches a dangerous distance, approximately $60 \mathrm{~cm}$, speed advantage is no longer necessary, since most snakes will not approach to bite humans.

In addition, Landová et al. (2018) recently noted that agreement in the evaluation of snake fear and also its beauty is cross-culturally high. They also found that the relative fear attributed to a selected snake species is not directly explainable by the current environmental and cultural differences (the Czech Republic and Azerbaijan) providing some support for the evolutionary hypothesis of preparedness to fear snakes.

It seems that more evidence is required to discard or prove the snake detection theory and to support alternative theories, and further studies are required to disprove or prove the snake detection theory. Albeit there is not yet clear evidence for a functional subcortical route for visual processing in primates (Pessoa and Adolphs, 2010), we also assume the possible existence of both innate and acquired learning processes in fear acquisition to snakes among primates in general. For example, Meno et al. (2013) noticed that white-faced capuchin monkeys (Cebus capucinus) infants as young as 1 month of age to call alarm at live snakes, which might reflect innate perceptual processes,

\section{REFERENCES}

Alirol, E., Sharma, S. K., Bawaskar, H. S., Kuch, U., and Chappuis, F. (2010). Snake bite in South Asia: a review. PLoS Negl. Trop. Dis. 4:e603. doi: 10.1371/ journal.pntd.0000603

Allen, W. L., Baddeley, R., Scott-Samuel, N. E., and Cuthill, I. C. (2013). The evolution and function of pattern diversity in snakes. Behav. Ecol. 24, 1237-1250. doi: 10.1093/beheco/art058 but there is later in development more detailed predator-recognition processes that require experiential and vicariant learning. Another example is the case of avian predators, innately programmed to flee when in startling proximity to something that resembles another species eye. But these eyes patterns do not exactly mimic any particular predator. Reactions vary in connection with the bird's learning ability, personal history of predator avoidance and experience, light level, proximity, degree of obstruction or hunger (Janzen et al., 2010; see also Hossie et al., 2015).

Taken together, we would like to draw attention to a potential bias caused by overreliance in controlled laboratory paradigms without naturalistic supportive feedback. Experiments using very simple schematic stimuli in order to control for low-level features are likely to lose some real value and should be confronted with ethobehavioral studies. Ecologically more valid studies could provide a way to study innate and learned fear interactions, and functional relationships in situations likely to occur in the wild (Pellman and Kim, 2016). Furthermore, theories that rely on general feature detection rather than detecting specific species seem more credible from an evolutionary psychology perspective.

\section{AUTHOR CONTRIBUTIONS}

CC and PS wrote the first draft of the manuscript. AF, FF-S, and $\mathrm{AZ}$ wrote sections of the manuscript. All authors contributed to the conception and design of the study and contributed to the manuscript revision, read, and approved the submitted version.

\section{FUNDING}

This research was supported by the Rachadapisek Sompote Fund for Postdoctoral Fellowship, Chulalongkorn University. AZ was supported by the ÚNKP-18-3-IV-PTE-9 New National Excellence Program of the Ministry of Human Capacities and by the European Union, co-financed by the European Social Fund. Comprehensive Development for Implementing Smart Specialization Strategies at the University of Pécs, grant no. EFOP-3.6.1.-16-2016-00004.

\section{ACKNOWLEDGMENTS}

We would like to thank Professor David Cundall for comments on earlier drafts and to three reviewers from the present journal and to the reviewers from previous submissions, in particular to Professor Lynne Isbell. Evol. Hum. Behav. 37, 303-314. doi: 10.1016/j.evolhumbehav.2016.01.006

Anderson, M. L. (2016). Précis of after phrenology: neural reuse and the interactive brain. Behav. Brain Sci. 39, 1-10. doi: 10.1017/S0140525X15000631

Araújo, M., and Martins, M. (2007). The defensive strike of five species of lanceheads of the genus Bothrops (Viperidae). Braz. J. Biol. 67, 327-332. doi: 10.1590/S1519-69842007000200019 
Ariaratnam, C. A., Sheriff, M. H. R., Arambepola, C., Theakston, R. D. G., and Warrell, D. (2009). Syndromic approach to treatment of snake bite in Sri Lanka based on results of a prospective national hospital-based survey of patients envenomed by identified snakes. Am. J. Trop. Med. Hyg. 81, 725-731. doi: 10.4269/ajtmh.2009.09-0225

Ariaratnam, C. A., Sheriff, M. R., Theakston, R. D. G., and Warrell, D. (2008). Distinctive epidemiologic and clinical features of common krait (Bungarus caeruleus) bites in Sri Lanka. Am. J. Trop. Med. Hyg. 79, 458-462. doi: 10.4269/ajtmh.2008.79.458

Badcock, P. B., Ploeger, A., and Allen, N. B. (2016). After phrenology: time for a paradigm shift in cognitive science. Behav. Brain Sci. 39, 10-11. doi: 10.1017/S0140525X15001557

Bawaskar, H., and Bawaskar, P. (2015). Snake bite poisoning. J. Mahatma Gandhi Ins. Med. Sci. 20, 5-14. doi: 10.4103/0971-9903.151717

Bawaskar, H., Bawaskar, P., Punde, D., Inamdar, M., Dongare, R., and Bhoite, R. (2008). Profile of snakebite envenoming in rural Maharashtra, India. J. Assoc. Physicians India 56, 88-95

Bawaskar, H., Saluba, H., Bawaskar, P., and Himmatrao, P. (2004). Envenoming by the common krait (Bungarus caeruleus) and Asian cobra (Naja naja): clinical manifestations and their management in a rural setting. Wilderness Environ. Med. 15, 257-266. doi: 10.1580/1080-6032(2004)015[0257:EBTCKB] 2.0.CO;2

Boissy, A. (1995). Fear and fearfulness in animals. Q. Rev. Biol. 70, 165-191. doi: $10.1086 / 418981$

Calvillo, D. P., and Hawkins, W. C. (2016). Animate objects are detected more frequently than inanimate objects in inattentional blindness tasks independently of threat. J. Gen. Psychol. 143, 101-115. doi: 10.1080/00221309.2016.1163249

Campbell, B. A., Wood, G., and McBride, T. (1997). "Origins of orienting and defensive responses: an evolutionary perspective" in Attention and orienting: Sensory and motivational processes. eds. P. J. Lang, R. F. Simons, and M. Balaban (New Jersey: Lawrence Erlbaum Associates, Inc.), 41-67.

Carretié, L., Hinojosa, J. A., Martín-Loeches, M., Mercado, F., and Tapia, M. (2004). Automatic attention to emotional stimuli: neural correlates. Hum. Brain Mapp. 22, 290-299. doi: 10.1002/hbm.20037

Casewell, N. R., Wüster, W., Vonk, F. J., Harrison, R. A., and Fry, B. G. (2013). Complex cocktails: the evolutionary novelty of venoms. Trends Ecol. Evol. 28, 219-229. doi: 10.1016/j.tree.2012.10.020

Cave, K. R., and Batty, M. J. (2006). From searching for features to searching for threat: drawing the boundary between preattentive and attentive vision. Vis. Cogn. 14, 629-646. doi: 10.1080/13506280500193107

Chippaux, J. P. (1998). Snake-bites: appraisal of the global situation. Bull. World Health Organ. 76, 515-524.

Clark, R. W., Tangco, S., and Barbour, M. A. (2012). Field video recordings reveal factors influencing predatory strike success of free-ranging rattlesnakes (Crotalus spp.). Anim. Behav. 84, 183-190. doi: 10.1016/j.anbehav.2012.04.029

Coelho, C. M., and Purkis, H. (2009). The origins of specific phobias: influential theories and current perspectives. Rev. Gen. Psychol. 13, 335-348. doi: $10.1037 / \mathrm{a} 0017759$

Cundall, D. (2002). "Envenomation strategies, head form, and feeding ecology in vipers" in Biology of the vipers. eds. G. W. Schuett, M. Hoggren, and E. M. Douglas (Eagle Mountain, UT: Eagle Mountain Publishing), 149-162.

Currie, B. J., Sutherland, S. K., Hudson, B. J., and Smith, A. M. (1991). An epidemiological study of snake bite envenomation in Papua New Guinea. Med. J. Aust. 154, 266-268

Davey, G. C. L. (1995). Preparedness and phobias: Specific evolved associations or a generalized expectancy bias? Behav. Brain Sci. 18, 289-325. doi: 10.1017/ s0140525x00038498

Deecke, V. B., Slater, P. J., and Ford, J. K. (2002). Selective habituation shapes acoustic predator recognition in harbour seals. Nature 420, 171-173. doi: 10.1038 /nature 01030

Deshwal, R., and Gupta, V. (2015). Krait envenomation disguised as heat exhaustion in a wilderness setting. Wilderness Environ. Med. 26, 102-104. doi: 10.1016/j.wem.2014.08.005

Fitzgerald, L. (2012). "Finding and capturing reptiles" in Reptile biodiversity: Standard methods for inventory and monitoring. eds. R. W. McDiarmid, M. S. Foster, C. Guyer, J. W. Gibbons, and N. Chernoff (Los Angeles: University of California Press), 77-80.

Flykt, A. (2006). Preparedness for action: responding to the snake in the grass. Am. J. Psychol. 1, 29-43. doi: 10.2307/20445317
Flykt, A., Bänziger, T., and Lindeberg, S. (2017). Intensity of vocal responses to spider and snake pictures in fearful individuals. Aust. J. Psychol. 69, 184-191. doi: 10.1111/ajpy.12137

Flykt, A., and Caldara, R. (2006). Tracking fear in snake and spider fearful participants during visual search: a multi-response domain study. Cognit. Emot. 20, 1075-1091. doi: 10.1080/02699930500381405

Flykt, A., Lindeberg, S., and Derakshan, N. (2012). Fear makes you stronger: responding to feared animal targets in visual search. Atten. Percept. Psychophys. 74, 1437-1445. doi: 10.3758/s13414-012-0336-6

Gibbons, J. W., and Dorcas, M. E. (2002). Defensive behavior of cottonmouths (Agkistrodon piscivorus) toward humans. Copeia 2002, 195-198. doi: 10.1643/0045-8511(2002)002[0195:DBOCAP]2.0.CO;2

Grassini, S., Holm, S. K., Railo, H., and Koivisto, M. (2016). Who is afraid of the invisible snake? Subjective visual awareness modulates posterior brain activity for evolutionarily threatening stimuli. Biol. Psychol. 121, 53-61. doi: 10.1016/j.biopsycho.2016.10.007

Gursky, S. (2003). Predation experiments on infant spectral tarsiers (Tarsius spectrum). Folia Primatol. 74, 272-284. doi: 10.1159/000073314

Haberkamp, A., Schmidt, F., and Schmidt, T. (2013). Rapid visuomotor processing of phobic images in spider-and snake-fearful participants. Acta Psychol. 144, 232-242. doi: 10.1016/j.actpsy.2013.07.001

Hansdak, S. G., Lallar, K. S., Pokharel, P., Shyangwa, P., Karki, P., and Koirala, S. (1998). A clinico-epidemiological study of snake bite in Nepal. Trop. Dr. 28, 223-226.

Hart, D., and Sussman, R. W. (2005). Man the hunted: Primates, predators, and human evolution. New York: Westview Press.

Headland, T. N., and Greene, H. W. (2011). Hunter-gatherers and other primates as prey, predators, and competitors of snakes. Proc. Natl. Acad. Sci. USA 108, E1470-E1474. doi: 10.1073/pnas.1115116108

Higham, T. E., Clark, R. W., Collins, C. E., Whitford, M. D., and Freymiller, G. A. (2017). Rattlesnakes are extremely fast and variable when striking at kangaroo rats in nature: three-dimensional high-speed kinematics at night. Sci. Rep. 7:40412. doi: $10.1038 /$ srep40412

Hossain, M. Z., Atiqullah, S., Saha, A. C., Chowdhury, A. J., Jahangir, K. M., and Faiz, M. A. (2010). A fatal cobra-bite in a snake expert. Mymensingh Med. J. 19, 303-307

Hossie, T. J., Skelhorn, J., Breinholt, J. W., Kawahara, A. Y., and Sherratt, T. N. (2015). Body size affects the evolution of eyespots in caterpillars. Proc. Natl. Acad. Sci. USA 112, 6664-6669. doi: 10.1073/pnas.1415121112

Isaac, L. A., and Gregory, P. T. (2013). Can snakes hide in plain view? Chromatic and achromatic crypsis of two colour forms of the Western terrestrial Garter Snake (Thamnophis elegans). Biol. J. Linn. Soc. 108, 756-772. doi: 10.1111/ bij. 12020

Isbell, L. A. (2006). Snakes as agents of evolutionary change in primate brains. J. Hum. Evol. 51, 1-35. doi: 10.1016/j.jhevol.2005.12.012

Isbell, L. A. (2009). The fruit, the tree, and the serpent. Cambridge, MA: Harvard University Press.

Isbell, L. A., and Etting, S. F. (2017). Scales drive detection, attention, and memory of snakes in wild vervet monkeys (Chlorocebus pygerythrus). Primates 58, 121-129. doi: 10.1007/s10329-016-0562-y

Jackson, R. E., and Calvillo, D. P. (2013). Evolutionary relevance facilitates visual processing. Evol. Psychol. 11, 1011-1026. doi: 10.1177/147470 491301100506

Jackson, J. F., Ingram, W. III., and Campbell, H. W. (1976). The dorsal pigmentation pattern of snakes as an antipredator strategy: a multivariate approach. Am. Nat. 110, 1029-1053. doi: 10.1086/283125

Janzen, D. H., Hallwachs, W., and Burns, J. M. (2010). A tropical horde of counterfeit predator eyes. Proc. Natl. Acad. Sci. USA 107, 11659-11665. doi: 10.1073/pnas.0912122107

Kardong, K. V., and Bels, V. L. (1998). Rattlesnake strike behavior: kinematics. J. Exp. Biol. 201, 837-850.

Kardong, K. V., and Smith, T. L. (2002). "Proximate factors involved in rattlesnake predatory behavior: a review" in Biology of the vipers. eds. G. W. Schuett, M. Hoggren, and E. M. Douglas (Eagle Mountain, UT: Eagle Mountain Publishing), 253-266.

Kasturiratne, A., Wickremasinghe, A. R., de Silva, N., Gunawardena, N. K. Pathmeswaran, A., Premaratna, R., et al. (2008). The global burden of snakebite: a literature analysis and modelling based on regional estimates of envenoming and deaths. PLoS Med. 5:e218. doi: 10.1371/journal.pmed.0050218 
Kawai, N., and He, H. (2016). Breaking snake camouflage: humans detect snakes more accurately than other animals under less discernible visual conditions. PLoS One 11:e0164342. doi: 10.1371/journal.pone.0164342

Krolak-Salmon, P., Hénaff, M.-A., Vighetto, A., Bertrand, O., and Mauguière, F. (2004). Early amygdala reaction to fear spreading in occipital, temporal, and frontal cortex: a depth electrode ERP study in human. Neuron 42, 665-676. doi: 10.1016/S0896-6273(04)00264-8

Kularatne, S. (2003). Epidemiology and clinical picture of the Russell's viper (Daboia russelii russelii) bite in Anuradhapura, Sri Lanka: a prospective study of 336 patients. Southeast Asian J. Trop. Med. Public Health 34, 855-862

Kularatne, K., Budagoda, S., Maduwage, K., Naser, K., Kumarasiri, R., and Kularatne, S. (2011). Parallels between Russell's viper (Daboia russelii) and hump-nosed viper (Hypnale species) bites in the central hills of Sri Lanka amidst the heavy burden of unidentified snake bites. Asian Pac. J. Trop. Med. 4, 564-567. doi: 10.1016/S1995-7645(11)60147-8

Kularatne, S., Silva, A., Weerakoon, K., Maduwage, K., Walathara, C., Paranagama, R., et al. (2014). Revisiting Russell's viper (Daboia russelii) bite in Sri Lanka: is abdominal pain an early feature of systemic envenoming? PLoS One 9:e90198. doi: 10.1371/journal.pone.0090198

LaDuc, T. J. (2002). "Does a quick offense equal a quick defense? Kinematic comparisons of predatory and defensive strikes in the western diamondbacked rattlesnake (Crotalus atrox)" in Biology of the vipers. eds. G. W. Schuett, M. Hoggren, and E. M. Douglas (Eagle Mountain, UT: Eagle Mountain Publishing), 267-278.

Lähteenmäki, M., Hyönä, J., Koivisto, M., and Nummenmaa, L. (2015). Affective processing requires awareness. J. Exp. Psychol. Gen. 144, 339-365. doi: $10.1037 /$ xge0000040

Landová, E., Bakhshaliyeva, N., Janovcová, M., Peléšková, Š., Suleymanova, M., Polák, J., et al. (2018). Association between fear and beauty evaluation of snakes: cross-cultural findings. Front. Psychol. 9:333. doi: 10.3389/fpsyg.2018.00333

Larson, C. L., Aronoff, J., Sarinopoulos, I. C., and Zhu, D. C. (2009). Recognizing threat: a simple geometric shape activates neural circuitry for threat detection. J. Cogn. Neurosci. 21, 1523-1535. doi: 10.1162/jocn.2009.21111

Larson, C. L., Aronoff, J., and Stearns, J. J. (2007). The shape of threat: simple geometric forms evoke rapid and sustained capture of attention. Emotion 7, 526-534. doi: 10.1037/1528-3542.7.3.526

Larson, C. L., Aronoff, J., and Steuer, E. L. (2012). Simple geometric shapes are implicitly associated with affective value. Motiv. Emot. 36, 404-413. doi: 10.1007/s11031-011-9249-2

LeDoux, J. (1998). The emotional brain: The mysterious underpinnings of emotional life. New York: Simon and Schuster.

LeDoux, J., Cicchetti, P., Xagoraris, A., and Romanski, L. M. (1990). The lateral amygdaloid nucleus: sensory interface of the amygdala in fear conditioning. J. Neurosci. 10, 1062-1069.

Liu, H., Agam, Y., Madsen, J. R., and Kreiman, G. (2009). Timing, timing, timing: fast decoding of object information from intracranial field potentials in human visual cortex. Neuron 62, 281-290. doi: 10.1016/j.neuron.2009.02.025

LoBue, V. (2014). Deconstructing the snake: the relative roles of perception, cognition, and emotion on threat detection. Emotion 14, 701-711. doi: 10.1037/a0035898

LoBue, V., and Rakison, D. (2013). What we fear most: a developmental advantage for threat-relevant stimuli. Dev. Rev. 33, 285-303. doi: 10.1016/j.dr.2013.07.005

LoBue, V., Rakison, D., and DeLoache, J. S. (2010). Threat perception across the lifespan: evidence for multiple converging pathways. Curr. Dir. Psychol. Sci. 19, 375-379. doi: 10.1177/0963721410388801

Maior, R. S., Hori, E., Barros, M., Teixeira, D. S., Tavares, M. C. H., Ono, T., et al. (2011). Superior colliculus lesions impair threat responsiveness in infant capuchin monkeys. Neurosci. Lett. 504, 257-260. doi: 10.1016/j.neulet.2011.09.042

Maritz, B. (2012). To run or hide? Escape behaviour in a cryptic african snake. Afr. Zool. 47, 270-274. doi: 10.1080/15627020.2012.11407555

McFadyen, J., Mermillod, M., Mattingley, J. B., Halász, V., and Garrido, M. I. (2017). A rapid subcortical amygdala route for faces irrespective of spatial frequency and emotion. J. Neurosci. 37, 3864-3874. doi: 10.1523/ JNEUROSCI.3525-16.2017

Meenatchisundaram, S., and Michael, A. (2009). Snake bite and therapeutic measures: Indian scenario. Indian J. Sci. Technol. 2, 69-73. doi: 10.17485/ ijst/2009/v2i10/30725

Méndez-Bértolo, C., Moratti, S., Toledano, R., Lopez-Sosa, F., Martínez-Alvarez, R., Mah, Y. H., et al. (2016). A fast pathway for fear in human amygdala. Nat. Neurosci. 19, 1041-1049. doi: 10.1038/nn.4324
Meno, W., Coss, R. G., and Perry, S. (2013). Development of Snake-directed antipredator behavior by wild white-faced capuchin monkeys: I. Snake-species discrimination. Am. J. Primatol. 75, 281-291. doi: 10.1002/ajp.22106

Mesulam, M.-M. (1998). From sensation to cognition. Brain 121, 1013-1052. doi: 10.1093/brain/121.6.1013

Minton, S. A. (1996). Bites by non-native venomous snakes in the United States. Wilderness Environ. Med. 7, 297-303. doi: 10.1580/1080-6032(1996)007[0297:BB NNVS]2.3.CO;2

Mormann, F., Dubois, J., Kornblith, S., Milosavljevic, M., Cerf, M., Ison, M., et al. (2011). A category-specific response to animals in the right human amygdala. Nat. Neurosci. 14, 1247-1249. doi: 10.1038/nn.2899

Morris, J. S., Öhman, A., and Dolan, R. J. (1999). A subcortical pathway to the right amygdala mediating "unseen" fear. Proc. Natl. Acad. Sci. USA 96, 1680-1685. doi: 10.1073/pnas.96.4.1680

Nairne, J. S., VanArsdall, J. E., Pandeirada, J. N., Cogdill, M., and LeBreton, J. M. (2013). Adaptive memory: the mnemonic value of animacy. Psychol. Sci. 24, 2099-2105. doi: 10.1177/0956797613480803

Nesse, R. M. (2001). The smoke detector principle. Ann. N. Y. Acad. Sci. 935, 75-85. doi: 10.1111/j.1749-6632.2001.tb03472.x

New, J., Cosmides, L., and Tooby, J. (2007). Category-specific attention for animal reflects ancestral priorities, not expertise. Proc. Natl. Acad. Sci. USA 104, 16598-16603. doi: 10.1073/pnas.0703913104

New, J., Schultz, R. T., Wolf, J., Niehaus, J. L., Klin, A., German, T. C., et al. (2010). The scope of social attention deficits in autism: prioritized orienting to people and animals in static natural scenes. Neuropsychologia 48, 51-59. doi: $10.1016 /$ j.neuropsychologia.2009.08.008

Niskanen, M., and Mappes, J. (2005). Significance of the dorsal zigzag pattern of Vipera latastei gaditana against avian predators. J. Anim. Ecol. 74, 1091-1101. doi: $10.1111 /$ j.1365-2656.2005.01008.x

Odedara, D. A. (2007). Snakebite: a clinical profile, epidemiology, prevalence, blind beliefs, medical treatment, prophylaxis and mortality in Saurashtra. doctoral dissertation. Rajkot, India: Saurashtra University. Retrieved from http://etheses.saurashtrauniversity.edu/id/eprint/579

Öhman, A., Eriksson, A., Fredriksson, M., Hugdahl, K., and Olofsson, C. (1974). Habituation of the electrodermal orienting reaction to potentially phobic and supposedly neutral stimuli in normal human subjects. Biol. Psychol. 2, 85-93. doi: 10.1016/0301-0511(74)90017-9

Öhman, A., Flykt, A., and Esteves, F. (2001). Emotion drives attention: detecting the snake in the grass. J. Exp. Psychol. Gen. 130, 466-478. doi: 10.1037/0096-3445.130.3.466

Öhman, A., and Mineka, S. (2003). The malicious serpent: snakes as a prototypical stimulus for an evolved module of fear. Curr. Dir. Psychol. Sci. 12, 5-9. doi: $10.1111 / 1467-8721.01211$

Öhman, A., and Soares, J. J. (1994). "Unconscious anxiety": phobic responses to masked stimuli. J. Abnorm. Psychol. 103, 231-240. doi: 10.1037/0021-843X.103.2.231

Ouattara, K., Lemasson, A., and Zuberbühler, K. (2009). Anti-predator strategies of free-ranging Campbell's monkeys. Behaviour 146, 1687-1708. doi: 10.1163/ 000579509X12469533725585

Paré, D., and Quirk, G. J. (2017). When scientific paradigms lead to tunnel vision: lessons from the study of fear. npj Sci. Learn. 2:6. doi: 10.1038/ s41539-017-0007-4

Pathan, J., Martin, A., Chowdhury, R., Chakrabarty, D., and Sarkar, A. (2015). Russell's viper venom affects regulation of small gGTPases and causes nuclear damage. Toxicon 108, 216-225. doi: 10.1016/j.toxicon.2015.10.011

Pellman, B. A., and Kim, J. J. (2016). What can ethobehavioral studies tell us about the brain's fear system? Trends Neurosci. 39, 420-431. doi: 10.1016/j. tins.2016.04.001

Penning, D. A., Sawvel, B., and Moon, B. R. (2016). Debunking the viper's strike: harmless snakes kill a common assumption. Biol. Lett. 12:20160011. doi: $10.1098 / \mathrm{rsbl} .2016 .0011$

Pessoa, L., and Adolphs, R. (2010). Emotion processing and the amygdala: from a'low road'to'many roads' of evaluating biological significance. Nat. Rev. Neurosci. 11, 773-783. doi: 10.1038/nrn2920

Pfister, M., Lue, J. L., Stefanini, F. R., Falabella, P., Dustin, L., Koss, M. J., et al. (2014). Comparison of reaction response time between hand and foot controlled devices in simulated microsurgical testing. Biomed. Res. Int. 2014:769296, 8 pages. doi: 10.1155/2014/769296

Poulton, E. B. (1890). The colours of animals. London: Kegan Paul, Trench, Trübner \& Co Ltd. 
Prokop, P., Fančovičová, J., and Kučerová, A. (2018). Aposematic colouration does not explain fear of snakes in humans. J. Ethol. 36, 35-41. doi: 10.1007/ s10164-017-0533-9

Punde, D. (2005). Management of snake-bite in rural Maharashtra: a 10-year experience. Natl Med. J. India 18, 71-75.

Purkis, H. M., and Lipp, O. V. (2007). Automatic attention does not equal automatic fear: preferential attention without implicit valence. Emotion 7, 314-323. doi: 10.1037/1528-3542.7.2.314

Quinlan, P. T. (2013). The visual detection of threat: a cautionary tale. Psychon. Bull. Rev. 20, 1080-1101. doi: 10.3758/s13423-013-0421-4

Rachman, S. J. (2002). Fears born and bred: Non-associative fear acquisition? Behav. Res. Ther. 40, 121-126. doi: 10.1016/s0005-7967(01)00044-4

Rahman, R., Faiz, M. A., Selim, S., Rahman, B., Basher, A., Jones, A., et al. (2010). Annual incidence of snake bite in rural Bangladesh. PLoS Negl. Trop. Dis. 4:e860. doi: 10.1371/journal.pntd.0000860

Rehbein, M. A., Steinberg, C., Wessing, I., Pastor, M. C., Zwitserlood, P., Keuper, K., et al. (2014). Rapid plasticity in the prefrontal cortex during affective associative learning. PLoS One 9:e110720. doi: 10.1371/journal.pone.0110720

Reid, H. A. (1975). Epidemiology of sea-snake bites. J. Trop. Med. Hyg. 78, 106-113

Schleidt, W. M. (1961). Reaktionen von Truthühnern auf fliegende Raubvögel und Versuche zur Analyse ihrer AAM's. Ethology 18, 534-560.

Schleidt, W. M., Shalter, M. D., and Moura-Neto, H. (2011). The hawk/goose story: the classical ethological experiments of Lorenz and Tinbergen, revisited. J. Comp. Psychol. 125, 121-133. doi: 10.1037/a0022068

Seligman, M. E. (1971). Phobias and preparedness. Behav. Ther. 2, 307-320. doi: 10.1016/S0005-7894(71)80064-3

Seyfarth, R. M., and Cheney, D. L. (1980). The ontogeny of vervet monkey alarm calling behavior: a preliminary report. Z. Tierpsychol. 54, 37-56.

Sharma, M., Gogoi, N., Dhananjaya, B., Menon, J. C., and Doley, R. (2014). Geographical variation of Indian Russell's viper venom and neutralization of its coagulopathy by polyvalent antivenom. Toxin Rev. 33, 7-15. doi: $10.3109 / 15569543.2013 .855789$

Silverstein, D. N., and Ingvar, M. (2015). A multi-pathway hypothesis for human visual fear signaling. Front. Syst. Neurosci. 9:101. doi: 10.3389/fnsys.2015.00101

Skelhorn, J., Holmes, G., Hossie, T. J., and Sherratt, T. N. (2015). Multi-component deceptive signals reduce the speed at which predators learn that prey are profitable. Behav. Ecol. 27, 141-147. doi: 10.1093/beheco/arv135

Soares, S. C. (2012). The lurking snake in the grass: interference of snake stimuli in visually taxing conditions. Evol. Psychol. 10, 187-197. doi: $10.1177 / 147470491201000202$

Soares, S. C., Lindström, B., Esteves, F., and Öhman, A. (2014). The hidden snake in the grass: superior detection of snakes in challenging attentional conditions. PLoS One 9:e114724. doi: 10.1371/journal.pone.0114724

Soares, S. C., Maior, R. S., Isbell, L. A., Tomaz, C., and Nishijo, H. (2017). Fast detector/first responder: interactions between the superior colliculuspulvinar pathway and stimuli relevant to primates. Front. Neurosci. 11:67. doi: $10.3389 /$ fnins.2017.00067

Subra, B., Muller, D., Fourgassie, L., Chauvin, A., and Alexopoulos, T. (2018). Of guns and snakes: testing a modern threat superiority effect. Cogn. Emot. 32, 81-91. doi: 10.1080/02699931.2017.1284044

Thorpe, S., Fize, D., and Marlot, C. (1996). Speed of processing in the human visual system. Nature 381, 520-522. doi: 10.1038/381520a0

Van Le, Q., Isbell, L. A., Matsumoto, J., Nguyen, M., Hori, E., Maior, R. S., et al. (2013). Pulvinar neurons reveal neurobiological evidence of past selection for rapid detection of snakes. Proc. Natl. Acad. Sci. USA 110, 19000-19005. doi: $10.1073 /$ pnas. 1312648110
Van Le, Q., Isbell, L. A., Matsumoto, J., Nishimaru, H., Hori, E., Maior, R. S., et al. (2016). Snakes elicit earlier, and monkey faces, later, gamma oscillations in macaque pulvinar neurons. Sci. Rep. 6:20595. doi: 10.1038/ srep20595

Van Strien, J. W., Christiaans, G., Franken, I. H., and Huijding, J. (2016). Curvilinear shapes and the snake detection hypothesis: an ERP study. Psychophysiology 53, 252-257. doi: 10.1111/psyp.12564

Van Strien, J. W., and Isbell, L. A. (2017). Snake scales, partial exposure, and the snake detection theory: a human ERP study. Sci. Rep. 7:46331. doi: $10.1038 /$ srep46331

VanRullen, R., and Thorpe, S. J. (2001). Is it a bird? Is it a plane? Ultra-rapid visual categorisation of natural and artifactual objects. Perception 30, 655-668. doi: $10.1068 / \mathrm{p} 3029$

Vlamings, P. H., Goffaux, V., and Kemner, C. (2009). Is the early modulation of brain activity by fearful facial expressions primarily mediated by coarse low spatial frequency information? J. Vis. 9, 12.1-12.13. doi: $10.1167 / 9.5 .12$

Warrell, D. (1995). "Clinical toxicology of snakebite in Africa and the Middle East/Arabian peninsula" in Handbook of clinical toxicology of animal venoms and poisons. eds. J. White and J. Meier (Boca Raton, FL: CRC Press), 433-492.

Whitaker, P., Ellis, K., and Shine, R. (2000). The defensive strike of the eastern Brownsnake, Pseudonaja textilis (Elapidae). Funct. Ecol. 14, 25-31. doi: 10.1046/j.1365-2435.2000.00385.x

Whitaker, P., and Shine, R. (1999a). Responses of free-ranging Brownsnakes (Pseudonaja textilis: Elapidae) to encounters with humans. Wildl. Res. 26, 689-704. doi: 10.1071/WR98042

Whitaker, P., and Shine, R. (1999b). When, where and why do people encounter australian brown-snakes (Pseudonaja textilis: Elapidae)? Wildl. Res. 26, 675-688. doi: 10.1071/WR98043

World Health Organization (2013). Animal bites (Fact sheet $\mathrm{N}^{\circ} 373$ ). Available at: http://www.who.int/mediacentre/factsheets/fs373/en/ (Accessed February 5, 2018).

Wüster, W. (1998). The cobras of the genus Naja in India. Hamadryad 23, 15-32.

Zsido, A. N., Bernath, L., Labadi, B., and Deak, A. (2018a). Count on arousal: introducing a new method for investigating the effects of emotional valence and arousal on visual search performance. Psychol. Res. 1-14. doi: 10.1007/ s00426-018-0974-y [Epub ahead of print].

Zsido, A. N., Deak, A., and Bernath, L. (2018b). Is a snake scarier than a gun? The ontogenetic-phylogenetic dispute from a new perspective: the role of arousal. Emotion 19, 726-732. doi: 10.1037/emo0000478

Zsido, A. N., Deak, A., Losonci, A., Stecina, D., Arato, A., and Bernath, L. (2018c). Investigating evolutionary constraints on the detection of threatening stimuli in preschool children. Acta Psychol. 185, 166-171. doi: 10.1016/j. actpsy.2018.02.009

Conflict of Interest Statement: The authors declare that the research was conducted in the absence of any commercial or financial relationships that could be construed as a potential conflict of interest.

Copyright (c) 2019 Coelho, Suttiwan, Faiz, Ferreira-Santos and Zsido. This is an open-access article distributed under the terms of the Creative Commons Attribution License (CC BY). The use, distribution or reproduction in other forums is permitted, provided the original author(s) and the copyright owner(s) are credited and that the original publication in this journal is cited, in accordance with accepted academic practice. No use, distribution or reproduction is permitted which does not comply with these terms. 